\title{
EL DIOS FAUNO Y EL RITUAL DE LOS LUPERCOS. REPRESENTACIONES DE LA DESNUDEZ MASCULINA* \\ God FAUNus AND THE RITUAL OF THE LUPERCI. REPRESENTATIONS OF THE MALE NUDITY
}

Borja Méndez Santiago UNIVERSIDAD DE OVIEDO MENDEZSBORJA@UNIOVI.ES

\section{RESUMEN}

Este trabajo pretende ofrecer, a través de un análisis iconográfico y literario, una nueva perspectiva acerca del grado de desnudez exhibido por los lupercos durante la celebración de las Lupercalias en Roma. Para ello, partimos del análisis de los principales temas que han abordado varias generaciones de estudiosos en relación con esta festividad para pasar, a continuación, a tratar de explicar, a través de las diferentes funciones del ritual, la finalidad de la ceremonia religiosa a los ojos de la propia sociedad romana. Finalmente, y

\section{Abstract}

This work aims to offer, through an iconographic and literary analysis, a new perspective towards the degree of nudity exhibited by the luperci during the celebration of the Lupercalia in Rome.

To reach this objective, we make a start with the analysis of the main topics that have been studied in relation to this holiday by several generations of scholars. We, then, go on to try to explain, through the different functions of the ritual, the purpose of this religious ceremony in the eyes of Roman

* Este artículo se inscribe en el marco del proyecto de investigación "HAR2017-82521-P: Maternidades, filiaciones y sentimientos en las sociedades griega y romana de la Antigüedad. Familias alternativas y otras relaciones de parentesco fuera de la norma", coordinado por Rosa María Cid López. 
haciendo uso de las únicas imágenes antiguas que de los lupercos han llegado hasta nuestros días, se busca dar cuenta de la evolución de su indumentaria. Así, trataremos de determinar hasta qué punto la opinión mayoritaria de la historiografía, según la cual, hasta Augusto, los lupercos exhibirían sus cuerpos desnudos, pero que tras sus reformas comenzarían a hacer uso de unas vestimentas mucho más pesadas, es válida o no. Esta supuesta variación de los atavíos sacerdotales tal vez guarde relación con cierto cambio fundamental que, auspiciado por Augusto, privó a los senadores de seguir ejerciendo como lupercos en favor de los caballeros. Los equites, que verían así ensalzada su posición social, terminarían siendo, a su vez, relegados de este papel en algún momento indeterminado de los siglos IV o V d. C., cuando sus antiguos roles pasaron a ser desempeñados por actores profesionales, lo que terminaría desvirtuando buena parte del contenido de un ritual ya milenario. society itself. Finally, and making use of the only ancient images of the luperci that have survived to this day, we seek to account for the evolution of their clothing.

Thus, we will try to determine to what extent the main opinion of historiography is valid or not - concerning the fact that the luperci, until Augustus, exhibited their naked bodies, but after his reforms they would start to use much heavier clothing -. This supposed variation of the priestly attire may be related to a certain fundamental change that, under the auspices of Augustus, deprived the senators of continuing to exercise as $l u$ perci in favor of knights. The equites - who would thus see their social status elevated -, would end up being, in turn, relegated from this role at some undetermined time in the IV or V centuries AD. After that, their old roles came to be played by professional actors, which would finally distort much of the content of this millennial ritual.

\section{Palabras Clave}

Desnudez, Lupercalias, lupercos, religión, ritual

\section{KEYWORDS}

Lupercalia, luperci, nudity, religion, ritual 
Siempre ha Resultado CHOCANTE CONSTATAR cómo, en la sociedad romana, pudo generarse y persistir en el tiempo una figura sacerdotal, la de los lupercos, que resultaba tan atípica desde todos los puntos de vista. Así, si por un lado sus integrantes nunca se asociaron en un solo collegium, sino en sodalitates, por otro su (semi)desnudez resultaba siempre difícil de explicar, sobre todo si comparamos la particular vestimenta exhibida por los lupercos con la pesadez de los atuendos portados por figuras como los pontifices, los flamines y los augures.

Sin embargo, esta (semi)desnudez de los lupercos rara vez ha sido estudiada por los historiadores de la religión antigua - más allá de su mera mención - a la luz de las fuentes literarias e iconográficas que han llegado hasta nuestros días. Por ello, en este texto trataré de analizar, en profundidad, la evolución histórica de la desnudez de los lupercos.

Desde la publicación de los primeros trabajos científicos respecto a las Lupercalias a mediados del siglo XIX, la discusión historiográfica se ha venido a centrar, particularmente, sobre una serie de temas que, en mi opinión, deben ser resaltados antes de dirigir nuestra visión a las distintas representaciones a través de las cuales indagaremos en la (semi)desnudez de los lupercos.

Ya autores como Franklin trataron de determinar, hace casi un siglo, la divinidad a la que los romanos consagraban las Lupercalias. ${ }^{1}$ Sin embargo, este autor, más que apuntar hacia una única deidad, se limitó a enunciar las que, a su juicio, eran las principales candidatas: Lupercus, ${ }^{2}$ Faunus, Inuus, ${ }^{3}$ Februus, Pan y Juno. A título meramente especulativo, algunos historiadores actuales han hecho notar que, ya en los tiempos de Cicerón, era bastante probable que la mayoría de los romanos hubieran olvidado el origen exacto de un ritual centenario que se hundía, para ellos, en la

1. Franklin, 1921, p. 18.

2. Véase Justino (Epitome a Pompeyo Trogo XLIII 1, 7). En opinión de Vé, 2018, p. 143, este Lupercus debe ser interpretado "non pas comme una divinité indépendante, mais (...) comme l'un des surnoms de Faunus en tant que dieu des Lupercales".

3. Son varios los autores que han identificado a esta divinidad como uno de los epítetos de Fauno. Véase nuevamente Vé, 2018, p. 142, n. 20, para bibliografía especializada. 
nebulosa de los tiempos. Una interesante teoría, sostenida por algunos especialistas recientes y basada en una referencia aislada de Festo, en la que los látigos de piel de cabra utilizados por los lupercos durante la ceremonia reciben el nombre de amicula Iunonis ("pequeños amigos de Juno"), ${ }^{4}$ ha sido utilizada para defender la dedicación de estas fiestas a la diosa Juno. ${ }^{5}$ Sin embargo, la mayor parte de los especialistas se decantan por considerar, apoyándose en testimonios a mi juicio incontestables - una de ellas, de índole artística, la comentaremos en la última sección del presente trabajo -, que el "dios de las Lupercalias" no sería otro que Fauno, el Pan Lykaeo arcadio. ${ }^{6}$

Otros autores, pese a la enorme dificultad de reconstruir el itinerario histórico de esta carrera ritual, han seguido escudriñando, una y otra vez, los textos clásicos, en un esfuerzo por reconstruir un itinerario fiable de la ceremonia que tenía lugar todos los años el 15 de febrero. Aunque los puntos de partida (la gruta del lupercal) y de llegada de la carrera (el foro) parecen claros, todavía se debate si el itinerario era circular ${ }^{7}$ o si, por el contrario, el recorrido adquiría otro tipo de forma. ${ }^{8}$ Más allá de consideraciones meramente topográficas, algunos especialistas se han llegado a cuestionar si debemos pensar que el recorrido permaneció inalterado a lo largo de más de 1200 años de historia o si, por el contrario, habría experimentado cambios a lo largo del tiempo. ${ }^{9}$

4. Fest. (Pablo LXXV 236). Las abreviaturas de los autores latinos se han extraído del Oxford Latin Dictionary; las referentes a los autores griegos, del Greek-English Lexicon.

5. North, 2008, pp. 149-150, critica explícitamente esta línea de argumentación. En su opinión, la mención a los amicula Iunonis debería ir en estrecha relación con Inuus. Así, "Iuno, the goddess (...) of childbirth, and Inuus, the god of sexual penetration, are found in collaboration together". Este tipo de argumentaciones pueden encontrar cierto refrendo iconográfico a través de una imagen que comentaremos más adelante (vid fig. 2).

6. Ya Rose, 1948, p. 58 afirmó que la mayor parte de los autores antiguos supuso que el ritual honraba a una deidad que, conceptualizada como un "macho cabrío parcialmente humanizado", sería identificable con el dios Pan. De ahí que otra de las cuestiones que más ha preocupado a la historiografía radique en ver si los lupercos hacían, bien de lobos, bien de machos cabríos. Autores de la talla de North, 2008, p. 148 y Rüpke, 2011, p. 73 han confirmado que, en su opinión, Pan es el mejor situado para ser el dios patrón de esta festividad tradicional romana.

7. Entre otros autores que se adhieren a esta teoría, quisiera destacar, entre otros, a Preller, 1858 y a Coarelli, 2012, pp. 140-141. Esta circularidad de la carrera ritual se mantuvo, al parecer, también en Constantinopla, donde sabemos que esta fiesta se siguió realizando, al menos, hasta el siglo X (véanse Munzi, 1994; Graf, 2015, pp. 175-183 y Krešimir, 2017). Los autores clásicos citados para sustentar esta teoría son, entre otros, Varrón (L.L. VI 34); Dionisio de Halicarnaso (I 80, 1) y Plutarco (Rom. XXI 6-7).

8. Michels, 1953, inauguró esta tendencia, que ha dado lugar a una importante polémica historiográfica, como tendremos ocasión de ver en la nota siguiente.

9. Ziolkowski, 1998-1999, p. 205 ha afirmado que "it would be strange if the scene of the ritual running and hitting remained constant during the twelve or so centuries of the festival existence". Así, en 
Una tercera cuestión bastante comentada por la historiografía tendría que ver con la división de los lupercos en dos colegios sacerdotales. ${ }^{10}$ Así, a partir de una historia narrada por Ovidio (Fast. II 361-380), se afirma que, mientras que Remo y los Fabii son los que finalmente sacrifican a Fauno, Rómulo y los Quintilii - al no recuperar el ganado que les había sido robado - son excluidos del consumo de la carne sacrificada. ${ }^{11}$ Para complicar las cosas, César crearía, durante su dictadura, un tercer "colegio" sacerdotal, el de los lupercos Iulianii, que ha dado origen a numerosas aportaciones a pesar de que sus integrantes tan solo corrieron en las Lupercalias del 44 a.C., famosas por el ofrecimiento de la corona por parte de Marco Antonio a Julio César. ${ }^{12}$ Otro tema que ha interesado a los especialistas ha sido el relativo al "estatus" de los lupercos. Así, mientras la práctica totalidad de los autores les reconocen su condición sacerdotal, ${ }^{13}$ existe una tendencia contraria, abanderada por Christoph Ulf, que les niega tal condición. ${ }^{14}$

\section{EVOLUCIÓN HISTÓRICA DEL RITUAL}

Quizás debiéramos comenzar nuestro acercamiento a las Lupercalias haciendo mención explícita a los actos celebrados el día de la fiesta, desde el sacrificio ritual matutino de una cabra y un perro (Plu., Rom. XXI 10) en la cueva del lupercal, ${ }^{15}$ hasta la carrera ritual que se cree tenía lugar por la falda del Palatino y con ocasión

su opinión, "the Luperci had no fixed route, but simply ran about 'everywhere people were gathered'". Para una opinión similar, cf. Wiseman, 1995b, p. 82. Coarelli 2005, pp. 32-37 critica esta aseveración destacando el carácter "stabile e conservatore" de los ritos religiosos. En este sentido, "l' introduzione di varianti, che talvolta si può constatare, è sempre ridotta al minimo, e corrisponde a trasformazioni strutturali".

10. Para Wiseman, 1995a, p. 12, las Lupercalias tal vez fueron reorganizadas en el 304 a.C., pues fue en ese momento cuando Quinto Fabio Máximo Ruliano, siendo censor, inauguró la transvectio equitum.

11. Krešimir, 2016, p. 49 afirma, con relación a estos dos grupos de lupercos, que es necesario distinguir un "tiempo mítico" de un "tiempo histórico". Así, "in mythical time, when Romulus and Remus walked the earth, their Luperci could be Fabii and Quintilii, but in historical time, members are recruited from various different families". Para un comentario de este pasaje, véase Robinson, 2011, pp. 252-263.

12. A este respecto, merece la pena destacar que Marco Antonio corrió en estas Lupercalias cuando ya tenía 39 años de edad. Respecto a estos colegios, resulta interesante la teoría de Wiseman, 1995b, pp. 80-81, que afirma que no todos sus miembros participarían en la carrera, aunque todos ellos se encontrarían presentes tanto en los ritos acaecidos en la cueva del Lupercal como durante los sacrificios. Sobre la edad "legal" de los lupercos, Vé, 2018, pp. 152-153, especula que vendría a coincidir con la de los iuniores (varones situados entre los 17 y los 45 años).

13. Vid, por todos, Wiseman, 1995b, p. 80.

14. Ulf, 1982, pp. 44-51.

15. Sobre la simbología de las cuevas en el mundo griego, cf. Ustinova, 2009. 
de la cual hombres jóvenes pertenecientes a la élite romana, ${ }^{16}$ ebrios, ${ }^{17}$ untados de aceite y desnudos, ${ }^{18}$ corrían azotando a quienes se encontraban con sus látigos de piel de cabra recién cortados. ${ }^{19}$ Sin embargo, la enumeración de todos estos hechos será en este trabajo soslayada, pues lo que me interesa verdaderamente aquí es presentar, esquemáticamente, algunas de las principales teorías que los estudiosos han esgrimido acerca de las funciones que cumplían las Lupercalias en el seno de la sociedad romana. Pese a que la mayor parte de las explicaciones se han querido presentar como excluyentes entre sí, lo cierto es que, por el contrario, tal vez debiéramos considerarlas acumulativas. ${ }^{20}$

Algunos autores han incidido en que las Lupercalias constituían una especie de "ritual carnavalesco". En este sentido, ya Dumézil afirmó, hace casi ochenta años, que "ont vu en les Luperques les représentants d' un désordre démoniaque et anarchique, en dehors de tout ordre civil". ${ }^{21}$ North, por su parte, nos ha proporcionado, en un interesante trabajo, una nueva clave interpretativa que, al menos, nos permite enten-

16. Vera Muñoz, 1990, p. 180 afirma, citando a Plutarco (Rom. XXI 6), que los lupercos eran, al menos originalmente, dos “jovencitos ( $\mu \varepsilon \rho \rho \alpha i \omega v)$ de familia noble”. Para los textos en latín o en griego original se han utilizado las ediciones bilingües de la Loeb Classical Library; las traducciones en castellano proceden en su totalidad de la Biblioteca Clásica Gredos.

17. Vid, por ejemplo, Valerio Máximo, II 2, 9 (epularum hilaritate ac vino largiori provecti).

18. Para la citación de estos tres aspectos, vid Cicerón, Phil. III 12 (Lupercorum mentionem facere audet neque illius diei memoriam perhorrescit quo ausus est obrutus vino, unguentis oblitus, nudus gementem populum Romanum ad servitutem cohortari?). Ferriès, 2009, p. 376, ha hecho un interesante análisis de este pasaje en el que advierte que, más que dar credibilidad absoluta a las palabras del arpinate, tal vez debiéramos comprender este furibundo ataque en el contexto general de las motivaciones de las Filípicas. En opinión de autores como Cordier, 2005, p. 204 el adjetivo latino nudus no es muy preciso, pues designa, en el espacio público, "tout registre vestimentaire inférieur à la toge, costume de rigueur pour les apparitions d' un Romain sur le forum avant l' Empire". Para una definición del término nudus como "having one's main garment removed", vid también, entre otros, Porte, 1976, p. 821, Bonfante, 1989, Hallett, 2005, pp. 61-62 y Graf, 2015, p. 165.

19. Wiseman, 2004, p. 79. Pese a las menciones de Festo (49L; 75-76L), en el sentido de que los lupercos tan solo azotaban a las mujeres, en realidad también eran vapuleados los asistentes masculinos, lo que parece cuadrar bastante bien con el carácter festivo de la carrera ritual.

20. Carandini y Bruno, 2008, p. 7, por ejemplo, afirman que la fiesta estaba destinada "alla purificazione di abitante e abitato, alla fecondità e al parto felice delle donne, alla nutrizione e alla salvazione dei neonati”.

21. Vid Dumézil, 1940, p. 7. Más adelante (1940, pp. 39-53) este autor afirmará que los lupercos, que imitaban la pastoralis iuventus reunida por Rómulo y Remo para recuperar el rebaño que se les había robado en el relato de Ovidio (también citado en Plutarco, Rom. XXI 9), constituían la variante romana de las conocidas antropológicamente como "sociedades de hombres". Esto ha llevado a que algunos autores, como Ulf, 1982, pp. 95-144, Potscher, 1984, p. 239, y Vé, 2018, pp. 158-161, entre otros, hayan considerado a las Lupercalias una especie de "rito de iniciación" de los jóvenes. Sin embargo, la conocida 
der mejor la última parte del ritual. Para él, la carrera no ha de ser vista como una especie de competición, sino más bien como un evento lúdico en el que el correteo de los lupercos se extendería a lo largo de toda una tarde. ${ }^{22}$ En opinión de este y otros investigadores, que parten claramente de los senderos metodológicos explorados por primera vez por Mijaíl Bajtín en su famoso estudio sobre Rabelais, ${ }^{23}$ las Lupercalias deben ser interpretadas como un ritual carnavalesco que confronta, durante un día al año, los conceptos de lo primitivo (representado por los lupercos) y lo civilizado (simbolizado por los asistentes). ${ }^{24}$ Corsano afirma que este tipo de festividades, al sustituir las normas tradicionales por un "ordre aberrant", buscan que las personas ambicionen la vuelta del "règne de la règle". 25

Para otros especialistas, las Lupercalias estarían estrechamente relacionadas con el mundo de ultratumba, ejerciendo la función de una especie de ritual purificatorio. Ferriès, que parte de una línea iniciada, entre otros, por Franklin ${ }^{26}$ y Green, ${ }^{27}$ afirma que, para Varrón (L.L. VI 13), "la fête est liée sans nul doute à la purification qui est l'essence même du mois de février", ${ }^{28}$ que se consideraba estrechamente relacionado con los dioses ctónicos. ${ }^{29}$ Autores como Binder, ${ }^{30}$ Alföldy, ${ }^{31}$ Brelich $^{32}$ o Holleman ${ }^{33}$ han llegado, desde postulados procedentes de la antropología, hasta una conclusión parecida. Así, para ellos los lupercos representarían a los ancestros ya fallecidos; los lupercos, al fustigar a los romanos y romanas que acudían a ver el ritual, no estarían

participación reiterada de algunos hombres en la carrera ritual - conocida a través de algunos epígrafes, como CIL VI 495 - ha llevado a autores como Rissanen, 2012, p. 127, a negar esta teoría.

22. North, 2008, p. 148.

23. Batjin, 1965.

24. Véase, por ejemplo, North, 2008, pp. 147-148. Estudiosos como Corsano, 1977, p. 145, Wiseman, 1995a, p. 1 y Marco Simón, 1996, p. 187, apoyándose en fuentes como Ovidio (Fast. II 282), han aprovechado aseveraciones como esta para tratar de explicar, de alguna manera, el extraño rol jugado en las Lupercalias por el Flamen Dialis. Vé, 2018, pp. 155-156, por ejemplo, afirma que esta figura sacerdotal representaría la antítesis del mundo salvaje encarnado por los lupercos. Sin embargo, autores como Rüpke, 2011, p. 73, más escépticos, niegan que a través de esta sola frase de Ovidio podamos reconstruir la función de este sacerdote en la ceremonia.

25. Corsano, 1977, p. 138.

26. Franklin, 1921, p. 19.

27. Green, 1931, p. 64.

28. Ferriès, 2009, p. 174. Munzi, 1994, p. 350, en su magnífico trabajo sobre la pervivencia de las Lupercalias en Constantinopla, también relaciona la fiesta en el marco más amplio de los dies parentales.

29. Aspecto este último ya mencionado, por ejemplo, por Plutarco, Rom. XXI 6.

30. Binder, 1964.

31. Alföldy, 1974.

32. Brelich, 1976, p. 119.

33. Holleman, 1985, p. 609. 
sino purificándolos de cara a las Parentalia, que tendrían lugar entre los días 13 y 21 de febrero de cada año. ${ }^{34}$ Para Néraudau - que compara las Lupercalias con los ludi Troiae -, nos encontramos ante "un rituel de conjuration de la mort". ${ }^{35}$

Según otros especialistas, las Lupercalias se encontrarían estrechamente relacionadas con la fertilidad. ${ }^{36}$ Una buena parte de los autores que defienden actualmente esta línea interpretativa considera que, sobre todo mediante la flagelación ritual de la espalda (o las manos) de las matronas romanas, se buscaba no solo garantizar la pervivencia de Roma, sino también promover la ausencia de enfermedades contagiosas y hambrunas; en este sentido, autores como Muccigrosso han defendido la idea de que, por ejemplo, la flagelación no era un elemento particularmente antiguo del ritual, sino que la misma fue insertada a raíz de dos epidemias acaecidas en 292 y 276 a.C. ${ }^{37}$ Thomas Köves-Zolauf, en un interesante trabajo, ha elaborado una sugerente teoría - difícil de probar - por la que los "elementos fertilizadores" del ritual no solo se encontrarían presentes en la segunda fase del mismo (la carrera), sino que se hallarían diseminados por toda ella. ${ }^{38}$ Para otros relevantes historiadores de la religión romana, como Wiseman ${ }^{39}$ y North, ${ }^{40}$ los lupercos estarían relacionados, de alguna manera, con Inuus, el dios de la penetración sexual (inire). ${ }^{41}$ Esta línea argumental se sustenta en algunos testimonios de los propios autores antiguos que, como Ovidio en sus Fasti, parecen aludir claramente a la relación de las Lupercalias con la fecundidad:
Nupta, quid exspectas? non tu pollentibus herbis
nec prece nec magico carmine mater eris;
excipe fecundae patienter uerbera dextrae,
iam socer optatum nomen habebit aui.

34. Rissanen, 2012, p. 126, afirma que, simbólicamente, los lupercos venían del Inframundo y que, tras su carrera ritual, volvían junto a los ancestros. Ziolkowski, 1998-1999, p. 203, también hace notar el carácter purificatorio del ritual en su conjunto. En su opinión, "the very name of February pushes the purificatory character of the Lupercalia to the regal period, if not to the dawn of Rome's history". Con el tiempo (concretamente, a partir del siglo III a.C.), afirma que las Lupercalias fueron perdiendo su función lustral en beneficio de su percepción como una ceremonia fecundadora.

35. Néraudau, 1979, p. 228.

36. Vid, por ejemplo, Ferri, 2010, p. 54.

37. Muccigrosso, 2006, p. 282. Para mayor información sobre esas supuestas epidemias, vid Wiseman, 1995b, p. 84 y n. 42 (con cita de fuentes y bibliografía al respecto).

38. Köves-Zolauf, 1990.

39. Wiseman, 1995a, p. 6.

40. North, 2008.

41. Oxford Classical Dictionary (1968). Vid ineo: "to go into", "enter" (a place). 
¿A qué esperas, desposada? No serás tú madre por el poder de las hierbas ni por las plegarias ni por encantamientos mágicos. Recibe pacientemente los latigazos de la diestra fecundadora y el suegro tendrá entonces el ansiado nombre de abuelo.

Ovidio, Fast. II 425-28 (trad. de Bartolomé Segura)

Finalmente, hay quien ha defendido que las Lupercalias se encontraban relacionadas con el fin del año romúleo y el inicio de la primavera. Autores que, como Granger, escribieron a finales del siglo XIX, expusieron ya la teoría de que esta festividad, sobre todo, celebraba la próxima llegada de la primavera. ${ }^{42}$ Aunque en la actualidad esta línea argumental no mantiene demasiado predicamento dentro de la historiografía, ha encontrado cierto apoyo por parte de North, ${ }^{43}$ quien ha afirmado que, al menos en la celebración de la fiesta en Constantinopla, la carrera ritual era seguida de un himno a la primavera. ${ }^{44}$

Una vez explicadas las principales teorías esgrimidas por la historiografía para tratar de discernir la(s) finalidad(es) de las Lupercalias, nos acercaremos brevemente a aquellas evoluciones producidas en la festividad que conocemos por medio de la literatura, pues el conocimiento de las mismas resulta, en mi opinión, indispensable antes de entrar a valorar, a través de los datos iconográficos disponibles, la evolución acaecida en la (semi)desnudez de los lupercos.

$\mathrm{Al}$ parecer, los propios romanos ya no se encontraban plenamente seguros de los orígenes del que, para ellos, era un antiquísimo ritual. ${ }^{45}$ Cicerón, por ejemplo, en un conocido fragmento de su Pro Caelio, asocia a los lupercos como figuras características de un universo precívico por medio de las siguientes palabras: “¡Cofradía feroz, francamente pastoricia y rústica ésta de los hermanos lupercos, cuya selvática alianza fue establecida antes que existieran la civilización y las leyes!" (trad. de Jesús Aspa Cereza). ${ }^{46}$ Este pasaje, junto con la historia contada por Ovidio en sus Fasti (II

42. Granger, 1895, p. 110.

43. North, 2008, pp. 156-157.

44. Graf, 2015, pp. 176-177, en su trabajo sobre la pervivencia de las Lupercalias en Constantinopla, recoge la traducción del Liber caerimoniarum de Albert Vogt (1935-1940), en la que se afirma que los lupercos, una vez que llegaban ante el tribunal, comenzaban a pronunciar una antifonía en la que, mien-

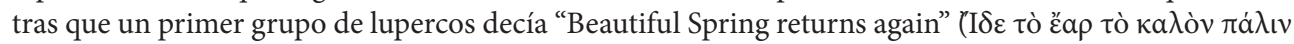

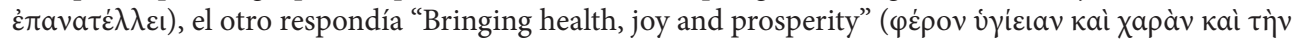

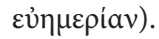

45. Mayorgas, 2010, p. 99 afirma que "The Lupercalia was the annual feast that reminded the Romans of the old times when Romulus and Remus lived among shepherds in a wild and rural environment".

46. Cicerón, Cael. 26: Fera quaedam sodalitas et plane pastoricia atque agrestis germanorum Lupercorum, quorum coitio illa siluestris ante est instituta quam humanitas atque leges. Autoridades como Negri, 
361-380), constituyen nuestras dos principales fuentes a la hora de entender cómo los romanos instruidos del siglo I a.C. imaginaban el origen y los aspectos más brumosos del ritual que veían celebrarse todos los años en las calles del Palatino y cuyos orígenes exactos parecían desconocer con exactitud.

Las reformas de César, como ya adelantaba en la introducción, se limitaron a la creación de una nueva sodalitas de lupercos (los Iulii). Sin embargo, los efectos de la misma fueron efímeros, pues este tercer grupo de lupercos no llegó a correr más que en una ocasión. Al parecer, las reformas de mayor enjundia fueron promovidas por Augusto, quien confió a los equites la responsabilidad de llevar a cabo este importante ritual y propició, en la línea del resto de su legislación sobre moralidad ciudadana, ${ }^{47}$ el establecimiento de una edad mínima para ejercer como luperco.$^{48}$ North y McLynn afirman que "if the reform belongs to the period of Augustus' main reforms and is supposedly reflected in the passage of Valerius Maximus, written in the reign of Tiberius, ${ }^{49}$ then we must accept the implication that all the early imperial sources - Ovid and Valerius Maximus writing in the early decades of the first century and Plutarch late in the first or early in the second century - are writing after this radical reform had taken place". ${ }^{50}$ Como consecuencia, estos autores afirman que los lupercos vieron cubiertas tanto la mayor parte de sus muslos como la parte inferior de sus torsos. Wiseman, incidiendo en este mismo aspecto, considera que, "in this more puritanical times, the demands of equestrian dignity had early compromised even more the traditional nudity of the luperci". ${ }^{51}$ Paralelamente (como puede verse en las representaciones de los lupercos que han llegado hasta nuestros días), los látigos utilizados ya

1982, y Holleman, 1985, han abogado por un origen itálico de la fiesta que se opone a la visión sostenida por parte de algunos autores clásicos que, como Dionisio de Halicarnaso (I 80, 1; I 32,3-4), la consideraban llegada - directamente a través de Evandro - de la Arcadia griega.

47. Ferriès, 2009, p. 373 afirma que, tras las reformas de César y Augusto, las anteriormente transgresivas Lupercalias pasaron a ser vistas como una “célébration vénérable". Esta línea de actuación circuló en paralelo con otras por las que, desde finales de la República, se trató erradicar ciertas conductas que se estaban volviendo populares entre la plebe. Sobre las mismas, vid Toner, 1995, pp. 79-80.

48. Suetonio (Aug. 31, 4) afirma que Lupercalibus uetuit currere imberbes. Para testimonios que hablan de esta desnudez de los lupercos acompañada de ungimientos de aceite, coronas y máscaras, véanse, entre otras referencias (todas ellas relacionadas, de una u otra manera, con la polémica celebración de las Lupercalias del 15 de febrero del 44 a.C.), Lactancio, Inst. I 21, 45; Dión Casio, XLV 30, 1; XLVI 5, 2-3; XLVI 17, 3; Plutarco, Ant. XII 1-12, 2; Nicolás de Damasco, Caes. XXI 71 y Cicerón, Phil. III 12; XIII 31.

49. Val. Max., II 2, 9.

50. North \& McLynn, 2008, p. 178.

51. Wiseman, 1995b, p. 83. Recientemente, un interesante artículo ha cuestionado la supuesta incidencia de las reformas de Augusto sobre la vestimenta de los lupercos. En opinión de su autora, no podemos extraer conclusiones definitivas respecto a la misma sobre la base de unas imágenes que nos 
no serían fabricados ex profeso, sino que los mismos habrían sido ya confeccionados con anterioridad. Este cambio se produjo, casi con total seguridad, para dotar a la fiesta de un mayor dinamismo, habida cuenta de que los distintos actos que debían ser realizados por los lupercos durante la primera fase del ritual (sacrificio de la cabra - y, en su caso, el perro -, el cocinado de la carne y su ingesta final) sin duda debían de mantenerles ocupados durante una buena parte de la jornada.

Después de estas reformas llevadas a cabo por Augusto, no disponemos de información literaria segura que nos permita conocer las modificaciones experimentadas por esta festividad religiosa, ni la iconografía nos permite atisbar si hubo algún cambio en el ritual mismo o referente a una indumentaria que (en apariencia) no sufrió cambios significativos durante el período analizado (ss. I a.C. - IV d.C.). Sin embargo, una interpretación que tome en cuenta la evolución de los gestos expresados por los personajes representados (especialmente por los lupercos) tal vez nos permita concluir que, con el tiempo, se intentó dotar al ceremonial de una mayor sensación de orden y ritualidad. Todo apunta a que fue el nacimiento y el desarrollo de una distinta concepción de la desnudez del cuerpo humano durante la época imperial uno de los motivos que no solo motivó un cambio en la extracción social de los lupercos, sino también una modificación paulatina en sus actitudes. ${ }^{52}$ De este modo, a medida que nos vamos acercando al fin del Imperio Romano podemos observar cómo el ritual se va desvirtualizando, pero no hasta el punto en que los ciudadanos romanos se mostraran incapaces de reconocerlo. Así, en la Roma de tiempos del Papa Gelasio (finales del siglo V d.C.) los lupercos - ya actores profesionales contratados por el promotor anual de la fiesta, el praefectus de turno -, todavía corrían (semi)desnudos en la creencia de que así mantenían a raya la aparición de las siempre temidas hambrunas y epidemias. ${ }^{53}$ En Constantinopla, donde el ritual se siguió celebrando al

muestran retratos de lupercos no corriendo ( $v i d$ fig. 5), sino posando (vid figs. 4, 6 y 7). Vid Guarisco, 2015, p. 225.

52. Sobre el desnudo romano véanse, por ejemplo, los interesantes análisis de Hallett, 2005 y Squire, 2011. Harper, 2013, p. 53 afirma que "The high empire was the Indian summer of classical nudity, when prosperity carried the culture of public baths and gymnasia further than ever before and even frankly erotic art was ubiquitous in refined and popular media". Pese a los intentos de estos autores, la tarea de realizar un estudio concienzudo acerca de la evolución de la concepción de la desnudez durante el Bajo Imperio todavía se encuentra, en buena medida, por realizar.

53. La baja extracción social de los participantes en el ritual a fines del siglo $\mathrm{V}$ d.C. queda patente cuando el Papa se refiere a ellos como ad viles trivialesque personas, abiectos et infimos (Adv. Andr. 16). Sobre la concepción de los actores en Roma y las penalizaciones que sufrían debido a su profesión, véanse las excelentes síntesis ofrecidas por Toner, 1995 (esp. p. 68) y Connolly, 2007, pp. 89-90. 
menos hasta el siglo $\mathrm{X},{ }^{54}$ también pervivieron algunos elementos de las Lupercalias originales, si bien altamente desvirtuados. ${ }^{55} \mathrm{Y}$, aunque en esos años los lupercos ya no corrían desnudos ni eran senadores o equites - se trataba de los aurigas más famosos de cada uno de los equipos que competían en el hipódromo de la antigua Bizancio -, todavía podemos ver cómo se mantienen, al menos, dos importantes funciones de la antigua ceremonia: por un lado, tras la carrera se elevaba un himno a la primavera ( vid n. 44) y, por otro, la subversión de los roles habituales quedaba de manifiesto, pues no deja de resultar "carnavalesco" que, por un día al año, los propios aurigas realizaran, en su pista de carreras habitual, una marcha a pie que les obligaba a ejercer el papel que normalmente desempeñaban sus monturas.

\section{UN RECORRIDO ICONOGRÁFICO POR EL CUERPO DE LOS LUPERCOS}

El análisis de la figura de los lupercos a través de los escasísimos restos iconográficos conservados resulta no solamente pertinente de cara a lograr un mejor conocimiento de la ceremonia y el modo en que los habitantes de Roma experimentaban este particular culto religioso, sino que nos permite, también, sumergirnos en un campo de estudio que, en mi opinión, todavía no ha sido suficientemente hollado por los autores que han ido publicando los distintos hallazgos iconográficos a medida que estos se iban produciendo. Estos testimonios artísticos, convenientemente analizados a la luz de los textos literarios conservados, tienen, por ejemplo, la capacidad de ayudarnos a comprender mejor aspectos tan interesantes como la evolución de la concepción social de la desnudez en Roma o su cambiante significado cultural. En este sentido, algunos estudiosos han incidido no solo en el carácter indispensable que tenía la toga como la vestimenta portada por los ciudadanos romanos en el espacio público, sino también en la importancia simbólica de la deposición de la misma realizada por los lupercos durante la festividad, cuya función era situar momentáneamente a estos jóvenes al margen de la ciudad y la civilización. ${ }^{56}$ En este sentido, entendemos que

54. Vid supra, n. 44.

55. Munzi, 1994, p. 351, afirma respecto a estas Lupercalias que "Certamente la festa bizantina aveva perduto al tempo di Costantino VII, ma probabilmente in stadi progressivi, molte delle caratteristiche originarie del culto pagano romano, riducendosi ad una cora ippica confinata nell' ippodromo, la dove ci saremmo aspettati un percorso di tipo lustrale ad esempio intorno al palazzo imperiale".

56. El más reciente de los autores consultados en este trabajo, Vé (2018, pp. 162-163), cita a fuentes clásicas como Plinio (NH. XVIII 20), Livio (III 26, 8-10) y Virgilio, (Aen. I 281-282) para apoyar su hipótesis sobre la importancia simbólica de la indumentaria ciudadana. Joseph, 1986, p. 1, afirmó, con carácter general, que la vestimenta "is very much a social artefact - a form of communication". 
los lupercos veían su temporal (semi)desnudez legitimada por la carrera ritual que llevaban a cabo todos los 15 de febrero. ${ }^{57}$

Iniciamos nuestro recorrido iconográfico, que pretende ser exhaustivo, con la imagen más antigua que se ha conservado, en Roma, del dios Pan (s. III a.C.). Hallado en Praeneste, en este espejo vemos a un itifálico Pan (identificado aquí como PAINSSCOS y asociado a la figura, conocida en la mitología griega, de Marsias) desnudo a excepción de una capa que le cubre desde los hombros hasta la parte baja de la espalda (fig. 1). Aunque pueda resultar osado, tal vez podríamos atribuir a los lupercos, al menos en un primer momento, una indumentaria muy similar a la que aquí se ha utilizado para representar al dios. En un momento posterior, para hacer referencia a la vestimenta de los lupercos, los autores clásicos comenzarán a utilizar términos como cinctuti, cincti o $\pi \varepsilon \rho \iota \zeta \omega \mu \alpha,{ }^{58}$ que aluden a lo que, en castellano, podríamos traducir como "taparrabos" ${ }^{59}$ Esta indumentaria, esta (semi)desnudez que tapa ya completamente los genitales masculinos de los lupercos, se encuentra en la base que cimentará las futuras representaciones de los lupercos - al menos, en aquellas imágenes que han tenido la suerte de llegar hasta nuestros días, salvo una excepción que comentaremos debidamente -. A falta de otra metodología mejor, trataremos de examinarlas a la luz de algunas de las noticias que, procedentes de la literatura de la época, han sido ya analizadas con anterioridad.

Disponemos de dos interesantes testimonios que nos muestran no a los lupercos de carne y hueso, sino al dios Fauno azotando (o en disposición de azotar) a personajes femeninos. En la primera de ellas (fig. 2), una imagen tallada sobre una gema a mediados del siglo I a.C., vemos el retrato - velado - de una joven romana que dirige su mirada hacia una figura con cuernos que, situada a la izquierda de la composición, puede ser fácilmente identificada como el dios Fauno portando en clara alusión a la actividad de los lupercos - un amiculum Iunonis. Tortorella avanza la hipótesis de que es posible que las mujeres que participaban en el festival de la flagelación llevaran una especie de velo realizado con la piel de la cabra que se sacrificaba antes de la carrera. ${ }^{60}$ Sin duda, mucho más interesante resulta la si-

57. Vid Toner, 1995, p. 59.

58. Cinctuti: Ovid., Fast. II 267; II 283-84; V 101; cincti: Val. Max., II 2, 9; $\pi \varepsilon \rho \iota \zeta \dot{\omega} \mu \alpha$ : Plu., Rom. XXI 5.

59. Loincloth, según los traductores de las ediciones bilingües de la Loeb Classical Library, que son las que se han manejado aquí para extraer los términos griegos y latinos utilizados. Festo, LL. 75-76; Virgilio, Aen. VIII 653; Fast. II 267; II 283-284; V 101 y Livio, I 5, 2, por ejemplo, son otras importantes fuentes en torno al grado de desnudez exhibido por los lupercos.

60. Wrede, 1995, p. 346; Tortorella, 2000, p. 245. Con todo, esta interpretación resulta bastante difícil de sostener, pues la misma parece implicar que, lejos de vagar libremente, los lupercos tan solo podrían fustigar a aquellas mujeres que llevaran este particular atuendo. 
guiente representación - un relieve muy poco estudiado que ocupa la parte trasera de un espejo -, que nos muestra a Venus siendo azotada por el dios Luperco ${ }^{61}$ o por Fauno (fig. 3). ${ }^{62}$ Iconográficamente, esta imagen resulta chocante, pues nos muestra a la diosa desnuda de cintura para abajo siendo sujetada de brazos y piernas por dos pequeños erotes mientras que un tercero parece anotar, sobre una tabula, el número de latigazos que la deidad recibe. Aunque muy difícil de datar con precisión, el primer estudioso en analizar el espejo ha tratado de conectarlo con la Fecunditas de Faustina la Menor o, alternativamente, con el culto de Venus Felix en la Velia. ${ }^{63}$ Tanto la posición de la diosa que va a ser flagelada como la importancia que la mirada parece tener en esta representación acercan esta composición a los relieves del sarcófago de Elia Afanacia, que comentaremos posteriormente (vid fig. 9), aunque aquí la diosa mantiene fija la mirada en su fustigador, no en uno de sus acompañantes. La figura del dios resulta también muy interesante: por un lado, por tratarse aparentemente de una figura de edad madura (vid también fig. 5) y, por otro, porque aparece desnudo de cintura para arriba de una manera que, como veremos, coincide con las formas de representación mayoritaria de los lupercos.

Mucho más interesante e ilustrativa de los lupercos "de carne y hueso" resulta la siguiente imagen (fig. 4) que nos muestra a un joven semidesnudo en posición de reposo. Inicialmente, tanto los descubridores de la estatua como sus primeros intérpretes pensaron que representaba a un victimarius, ${ }^{64}$ sin embargo, en la actualidad existe cierto consenso a la hora de considerarla el retrato de un luperco, principalmente por los exiguos restos del objeto que la figura portaba en su mano derecha, y que han sido identificados por Tortorella como pertenecientes a la empuñadura del látigo (februum) empleado por estos personajes. ${ }^{65}$ Datable en el primer tercio del siglo I d.C., esta escultura resulta interesante para nuestros fines, dado que inaugura una manera de representar a los lupercos que tendrá cierto recorrido futuro, como demuestra la imagen principal de una de las caras del altar de Tiberio Claudio Liberal (fig. 6) que comentaremos más adelante. Desde una perspectiva iconográfica, el

61. Wrede, 1995, p. 345.

62. Tortorella, 2000, p. 245.

63. Wrede, 1995, p. 346.

64. Faccenna, 1954, p. 24, afirma que el joven llevaría, en su mano derecha, un aspergillum, elemento que servía para la purificación de las víctimas durante los sacrificios. Wrede, 1983, p. 189-194, por su parte, alude a varios paralelos iconográficos para cimentar esta misma identificación.

65. Tortorella, 2000, p. 248. 
joven luperco aparece desnudo de cintura para arriba, portando un taparrabos que, anudado alrededor de su cintura, se extiende hasta justo por encima de sus rodillas. ${ }^{66}$

Una placa de arcilla hallada durante las excavaciones francesas en la Casa de Livia en 1869 resulta especialmente interesante para nosotros, en tanto que único ejemplo procedente del mundo antiguo que nos muestra a los lupercos desnudos y durante el desempeño de la carrera ritual. ${ }^{67}$ En la representación aparecen, de manera fragmentaria, tres jóvenes lupercos que, completamente desnudos, portan el amiculum iunonis en sus manos. ${ }^{68} \mathrm{~A}$ la izquierda de la composición, un cuarto luperco - que todavía no ha comenzado a correr - aparece mirando hacia algún punto situado detrás del espectador mientras aferra con su mano derecha el látigo que denota la actividad que se encuentra llevando a cabo. ${ }^{69}$ Más allá de la identificación de la escena, resulta interesante constatar el contraste existente entre los cuerpos jóvenes y relativamente enjutos de las tres figuras fragmentarias con la constitución más gruesa del luperco situado en primer término, que en opinión de algunos comentaristas de la imagen tal vez podría tratarse del magister lupercorum. ${ }^{70}$ Volviendo a la desnudez de las figuras representadas, resulta muy tentador considerar que las reformas de Augusto sobre las Lupercalias (Suetonio, Aug. 31, 4), lejos de modificar la vestimenta de los lupercos durante la ceremonia, tan solo afectaron a la extracción social de los mismos y a la edad con la que podían desempeñar esta función. Sobre la base de lo apenas dicho, la desnudez de los lupercos que atestigua esta placa de arcilla tal vez pueda fundamentarse sobre la base de que, a diferencia del resto de imágenes que hemos visto (fig. 4) y que veremos (figs. 6-7), lo que aquí se representa no es la manera en que los lupercos pretendían ser recordados, sino el atuendo con el que efectivamente desempeñaban su función ritual las tardes del 15 de febrero.

Wiseman, que no tiene en cuenta esta imagen a la hora de elaborar sus hipótesis, afirma que, desde Augusto en adelante, es muy probable que las preocupaciones morales suscitadas por esta fiesta transgresora aumentaran. ${ }^{71}$ Tal situación se percibiría,

66. Plinio el Viejo (NH. XXXIV 10,18) afirma que las estatuas que representaban a los lupercos eran una innovación de su época (nam Lupercorum habitu tam noviciae sunt...).

67. Tomey, 1999, p. 438.

68. El primer estudioso que analizó la placa encuadró la escena - debido a la desnudez de los jóvenes - en el interior de un gimnasio. Vid Von Rohden y Winnefeld, 1911, p. 152.

69. Tortorella, 2000 p. 251 afirma que "è comunque probabile che una flagellazione fosse raffigurata nella metà mancante della lastra".

70. Alonso, 2017, p. 49, aunque es más probable que cada sodalitas tuviera a su propio magister.

71. Wiseman, 1995b, p. 83. Como veremos, todo apunta a que este proceso se aceleraría en los siglos II y III d.C., momento en el que tuvo lugar un profundo cambio en la percepción social de la desnudez 
por ejemplo - además de en el texto ya mencionado de Suetonio inserto en la Vida de Augusto $-{ }^{72}$ en los relieves que acompañan el epígrafe funerario del joven Tiberio Claudio Liberal (fig. 6). Estudiada por primera vez por Paul Veyne en $1960,{ }^{73}$ sus relieves nos muestran a un joven eques fallecido a los dieciséis años de edad ejerciendo los roles que (tal vez) no pudo llegar a llevar a cabo en vida ${ }^{74}$. En concreto, si la imagen central nos lo muestra - coronado - montado a caballo en la conocida como transvectio equitum, parada militar a caballo que tenía lugar todos los idus de julio, ${ }^{75}$ en la imagen de la derecha lo vemos ataviado como un luperco. ${ }^{76} \mathrm{Y}$ es que, a partir de la imagen del luperco de Fondi (fig. 4), la representación-tipo de los lupercos quedó fijada hasta el siglo IV d.C., si bien en las dos últimas imágenes que comentaremos (figs. 8 y 9) se decididiría representar a los lupercos no en reposo, sino en el acto de golpear a las mujeres con sus látigos. Volviendo de nuevo a esta imagen, llama la atención que el amiculum Iunonis ya no parezca realizado ex profeso tras el sacrificio de la cabra, sino confeccionado con anterioridad. Tanto el epígrafe del altar (vid infra) como las imágenes que lo acompañan han sido datados por la mayor parte de los especialistas en el siglo II d.C., por lo que tal vez no sería descabellado - sobre todo en ausencia de otros testimonios a través de los cuales establecer comparaciones otorgar a esta representación iconográfica el valor de "documento histórico" acerca del grado de desnudez exhibido por los lupercos durante los reinados de los emperadores Trajano y Adriano. ${ }^{77}$

TI. CLAUDIO LIBERALI

PRAEF. FABR. EQVO

PUBLICO FILIO OPTIMO

humana, cuya exhibición pública - al menos en contextos religiosos - comenzó a ser considerada inadecuada.

72. Suet., Aug. 31, 4 (vid supra, n. 48).

73. Veyne, 1960, p. 200. Para más información acerca de esta parada ecuestre y su vinculación con las Lupercalias, véanse Wiseman, 1995a, p. 12 y North \& McLynn, 2008, p. 178. Estos dos últimos autores, por ejemplo, han incidido notablemente en la importancia de esta ceremonia en relación con la iniciación de los caballeros (equites), que de este modo se presentaban públicamente ante la sociedad como miembros capaces de defenderla frente a los peligros externos.

74. Graf, 2015, p. 164 afirma, de manera muy convincente, que ser nombrado luperco constituía un gran paso adelante en el cursus honorum de un eques.

75. Wiseman, 1995a, p. 12.

76. Adviértase que el término "luperco" no es aquí utilizado. Por el contrario, a Tiberio se le denomina sodalis desiderantissimus (cf. Tortorella, 2000, p. 249; North \& McLynn, 2008, p. 178).

77. Wrede, 1983, p. 187 se ha basado, para ofrecer esta datación, tanto en los elementos estilísticos de la inscripción como en los peinados exhibidos por los personajes representados. 
PIISIMO DULCISSIMO

SODALI DESIDERANTISSIM

VIXIT . ANNIS . XVI

MENSIBVS. V. DIEBUS.XXI

PARENTES INFELICISSIMI

Un relieve similar, datado en el siglo II d.C. y conservado en el museo del Samnio (Benevento), nos muestra, exactamente, las mismas dos escenas que hemos mencionado antes (la transvectio equitum - a la izquierda - y a un luperco - a la derecha -) (fig. 7). Aunque su pobre estado de conservación no nos permite realizar demasiadas elucubraciones al respecto, sí podemos utilizarlo, al menos, para constatar la fijación de ciertos convencionalismos estilísticos en relación a la figura de los lupercos. En conexión con la imagen anterior (fig. 6), resulta importante destacar la estrecha relación que los propios equites establecieron entre dos festividades que, al parecer, llegaron a erigirse, para ellos, en importantes medios para la conformación de su propia identidad social en tanto que ciudadanos romanos.

La siguiente representación, procedente de un mosaico de grandes dimensiones hallado en Thysdrus (el-Djem, Túnez), nos muestra a un luperco en el acto de azotar con su látigo de piel de cabra a una mujer, que ya no le ofrece voluntariamente su espalda (Ov., Fast. 2.445-6) o sus manos (Plu., Caes. 61.2; Juv., 2.142), sino que es sujetada por dos de sus acompañantes (fig. 8). Autores como North y McLynn, dos de los principales comentaristas de la imagen, afirman, en una breve aportación colectiva, que, tanto en el caso de este mosaico, como en el de la imagen posterior, ya no se muestra un golpeo "como de pasada", sino un "azote deliberado" (deliberate beating) en el que, además, debemos hacer notar el contraste existente entre la dignidad de la postura del luperco - acompañado de dos asistentes y vestido con una especie de delantal cuadrangular ${ }^{78}$ - con la exposición descuidada e indigna del cuerpo de la mujer que va a ser lacerada. ${ }^{79}$ En cuanto a la figura del luperco, resulta muy interesante constatar que, a diferencia de las dos imágenes anteriormente comentadas, aquí el luperco está cubierto por lo que parece ser un pantaloncillo hasta por debajo de las rodillas. Autores como Holleman avanzan la hipótesis de que la testa del joven - que ya no procedería del rango de los equites, sino que sería un actor contratado ex pro-

78. Wrede, 1983, p. 187.

79. North \& McLynn, 2008, p. 179 advierten también que el azotamiento de la mujer es presentado como si fuera una especie de espectáculo, y se preguntan, muy acertadamente en mi opinión, si lo que vemos en este tipo de representaciones (también en la fig. 5) respondía a la realidad de cada 15 de febrero o, por el contrario, lo que trataban era de "velar" la desnudez de los lupercos. 
feso para llevar a cabo la parte física de la ceremonia - se encontraba enmascarada, ${ }^{80}$ extremo bastante difícil de probar habida cuenta el precario estado de conservación en el que se encuentra el mosaico, que ha sido datado tanto por su descubridor Foucher $^{81}$ como por autores como Stern ${ }^{82}$ en el siglo III d. C., muy probablemente en su primera mitad (como muy tarde durante el reinado de Alejandro Severo).

Cerramos el análisis iconográfico de este trabajo exponiendo algunas cuestiones relacionadas con el sarcófago de Elia Afanacia (fig. 5). ${ }^{83}$ Aunque estos relieves fueron realizados a finales del siglo III, lo cierto es que su temática pagana no fue óbice para su reutilización en la tumba de una joven cristiana ya a mediados del siglo IV d.C. ${ }^{84}$ En cuanto a la figura del luperco, podemos destacar, como ya hiciéramos en relación con el mosaico de Thysdrus, la contraposición existente entre la "dignidad" atribuida al cuerpo del luperco ${ }^{85}$ que ya solo enseña parte de su torso, y la imagen de una mujer que, agarrada como si se tratara de un animal y semidesnuda, aparece a punto de ser azotada. ${ }^{86}$ Aquí, el luperco viste una especie de faldellín que le cubre desde la parte superior de las rodillas hasta la cintura y una extraña vestimenta (una especie de faja) que se extiende, prácticamente, hasta la parte inferior del pecho. En línea con lo ya

80. Holleman, 1974, p. 139.

81. Foucher, 1963.

82. Stern, 1968.

83. Sobre el mismo véanse, por ejemplo, los comentarios de Schumacher, 1968-1969, pp. 65-75; Solin y Brandenburg, 1980, pp. 271-284; Wiseman, 1995a, pp. 16-17; Tortorella, 2000, p. 253 y McLynn, 2008, p. 168.

84. Koch, 2017, p. 537 afirma que este relieve tal vez no represente el azote de una mujer durante las lupercalias sino, más bien, la flagelación de una mártir cristiana. Sin embargo, el hecho de que el personaje masculino situado a la derecha de la composición (junto a la inscripción conmemorativa) porte un vexillum (elemento presente, también, la imagen del altar de Claudio Liberal) habla en favor de que esta escena fuera inicialmente pensada para representar unas Lupercalias (vid Tortorella, 2000, p. 253).

85. Autores como Wiseman, 1995a, y McLynn, 2008, p. 169 interpretan que este relieve demuestra, en comparación con los ejemplos anteriores, una mayor consideración social de los lupercos. El último de los autores aquí señalados, por ejemplo, afirma que le resulta "tentador" (tempting) pensar que, por estas fechas, los senadores hubieran vuelto a recuperar el control sobre un ritual, que, como sabemos, Augusto cediera tiempo atrás a los equites. Aunque nunca podremos probar este extremo, el detalle iconográfico del vexillum al que acabamos de hacer alusión habla en favor de que, a menos a la fecha de realización del relieve, los equites seguían manteniendo algún tipo de control sobre el ritual.

86. Una posible explicación a esta desigualdad en el tratamiento de las figuras masculinas y femeninas tal vez pase por contraponer extracción social del luperco - todavía un eques - con la de la mujer que es azotada (probablemente una actriz contratada). Adviértase que, mientras que en el sarcófago (o en la fig. 3), la mujer va a ser fustigada en la espalda o en los glúteos, en el mosaico de Thysdrus la flagelación va a tener lugar (aparentemente) en el vientre o en los muslos de la figura femenina (vid Holleman, 1974, p. 142). 
anteriormente expuesto a propósito del mosaico de Thysdrus, los lupercos - aparentemente - cada vez aparecen menos desnudos ante la mirada pública, aunque los cambios no parecen ser demasiado acusados. Para autoras como Alonso, "The female of the sarcophagus is exposing herself to the whipping in a conscious and open way: she throws herself into the multitude of Luperci and stares directly at the person who is holding her arms". ${ }^{87}$ En este contexto, pues, resulta muy difícil pensar en una participación abierta al público en la que, por ejemplo, colaboraran activamente las matronas que habían desempeñado un papel tan importante en el ritual al menos hasta los tiempos de Augusto. De hecho, autores como North y McLynn han puesto de relieve, muy acertadamente en mi opinión, la progresiva teatralización de un acontecimiento público que, con el tiempo, acabaría siendo llevado a cabo cada año por actores profesionales (de ambos sexos) que eran contratados a tal efecto por el praefectus que ostentara el cargo en ese momento. ${ }^{88}$ Con todo, esta desvirtualización de la jornada del 15 de febrero (al menos, de la carrera ritual) ${ }^{89}$ no consiguió que buena parte de la población olvidara su sentido último ${ }^{90}$. Así, en la ya mencionada obra Contra Andrómaco, escrita a finales del siglo V, vemos cómo uno de los partidarios del ritual - el mismo senador Andrómaco que da nombre al tratado - ${ }^{91}$ advertía que, en caso de que se suprimiera, "the city [Rome] was being deprived of its protection against pestilence and famine" ( $A d v$. Andr. III 13, 23); este aspecto prueba, en nuestra opinión, la pervivencia, al menos entre la élite tardoantigua, de una consciencia clara

87. Alonso, 2017, p. 54

88. North \& McLynn, 2008, p. 180. McLynn, 2008, pp. 171-172, individualmente, afirma que, al menos en el siglo V d.C., "the Lupercalia should therefore be seen as an annual option for the official in charge", y que le daba a este la oportunidad de exhibir, a un público romano ya mayoritariamente cristiano, una de las fiestas tradicionales más famosas de la antigua Roma pagana. Ciertamente, no podemos saber cuándo los miembros del ordo ecuestre perdieron su posición como lupercos en favor de estos actores profesionales. Tan solo podemos afirmar que este cambio - de haberse producido efectivamente - tuvo lugar entre los siglos IV y V d.C.

89. Que es, por otra parte, la única que ha dejado huellas - si bien pocas, como hemos visto - en el imaginario artístico romano.

90. Cameron, 2011, p. 170 afirma, por el contrario, que el festival estaría ya tan desvirtuado que sus elementos paganos tan solo podrían ser percibidos por la élite más culta.

91. Autores como McLynn, 2008, pp. 163-164, yendo más allá del comentario habitual, que suele limitarse a citar una frase muy conocida de la argumentación del Papa (vid supra, n. 53), se preocupa por discernir cuestiones que, como el género de esta obrita, nos permiten entender mejor tanto el contexto en el que fue escrita como sus finalidades. Este trabajo prueba que el escrito del Papa Gelasio, más que promover la erradicación definitiva de las Lupercalias - el Papa no tenía autoridad o poder para hacerlo -, tan solo pretendía contribuir al debate de la época demostrando que las Lupercalias no solo eran inútiles, sino también contrarias a la "verdadera religión" (contraria verae religioni; Adv. Andr. 31; ed. Pomarès 1959). 
acerca del valor taumatúrgico de un ritual antiquísimo que llevaba, por entonces, más de 1.200 años teniendo lugar a lo largo de las faldas del Palatino.

\section{A MODO DE CONCLUSIÓN}

En este texto se trató de reconstruir el grado de desnudez exhibido por los lupercos durante la festividad de las Lupercalias, que recorrió las calles del centro neurálgico de la ciudad de Roma cada 15 de febrero todos los años durante más de un milenio. En nuestro análisis hemos partido de la exposición de los principales temas que han interesado a la historiografía en torno a las Lupercalias (especialmente la identificación de la deidad patrona de la festividad y la funcionalidad de la misma) para tratar de ofrecer una nueva lectura de las imágenes que se han conservado de los lupercos. Estos, como hemos visto, eran asociados ya por los propios romanos del siglo I a.C. con un pasado salvaje y precívico que se hundía en el pasado remoto (vid, por ejemplo, Cic., Cael. 26) hasta el punto de que ellos mismos no parecen haber sido conscientes de los orígenes últimos del ritual antiquísimo que tenía lugar cada año ante ellos.

A partir de la información de estos textos, algunos historiadores plantearon la posibilidad de que las reformas de Augusto supusieran un antes y un después en la festividad, tanto en lo relativo a la edad y extracción social de los lupercos como en relación a la vestimenta por ellos utilizada. Así, para algunos especialistas las modificaciones introducidas por el fundador del Principado habrían motivado que los lupercos abandonaran su tradicional desnudez ( $v i d$ figs. 1 y 5) en favor de una especie de taparrabos que ocultara sus miembros de la mirada de los asistentes. Este último hecho, sin embargo, no solo no ha podido ser confirmado de forma concluyente en el presente trabajo, sino que nuestras indagaciones nos llevan, más bien, a cuestionarlo seriamente. Así, por sí solos, los documentos iconográficos que nos muestran a los lupercos "de carne y hueso" vestidos (figs. 4, 6-9) ni confirman ni desmienten la existencia de un supuesto primer estadio de desnudez de estos personajes. De hecho, la placa de arcilla descubierta en las inmediaciones de la Casa de Livia (fig. 5) invita a sostener, por el contrario, que es probable que Augusto no introdujera cambio alguno en la indumentaria de los lupercos, que continuarían corriendo desnudos. Esta representación, además, se erige en un testimonio único pues, además de ser algo anterior en el tiempo a las ya mencionadas, datadas en los siglos I-III d.C., y mostrarnos a un grupo de tres lupercos, exhibe a los mismos no en actitud de reposo (figs. 4, 6) o en la acción de azotar a una figura femenina (figs. 8-9), sino durante el ejercicio de la carrera ritual.

Con el afán de profundizar en lo apenas expuesto, hemos de reconocer la falta de una base de testimonios sólida que nos permita dilucidar si estas representacio- 
nes responden fielmente a la indumentaria real exhibida por los lupercos durante el desempeño de sus funciones rituales o, por el contrario, se derivan de la manera en que estos deseaban ser recordados. ${ }^{92}$ Lo cierto es que, con independencia de cuándo hayan surgido realmente - si durante los tiempos de Augusto o tras el triunfo del Cristianismo en el Imperio Romano -, las modificaciones relativas a la concepción del cuerpo humano desnudo propiciaron una serie de cambios sobre este ritual que llevarían a que, con el tiempo, los propios aristócratas que venían encargándose tradicionalmente del mismo se terminaran mostrando reacios a la hora de desempeñar públicamente sus funciones como lupercos, prefiriendo relegar estas tareas en otras personas que, como los actores, gozaban de una menor consideración social. ${ }^{33}$ Los cristianos cultos contrarios a la festividad encontraron, entonces, un argumento más a la hora de domesticar una antiquísima festividad que corría el riesgo de continuar pervirtiendo las "débiles mentes" de los cristianos corrientes que habían pasado a ser, ya en la tardoantigüedad, sus espectadores mayoritarios. ${ }^{94}$

\section{Agradecimiento}

Por último, quisiera agradecer a los evaluadores anónimos de la revista su gentileza a la hora de señalarme las carencias de la versión inicial de este trabajo. En este sentido, sus agudos comentarios y observaciones han contribuido a limitar los errores y las incoherencias presentes en este texto.

92. North \& McLynn, 2008, p. 180.

93. Graf, 2015, p. 173.

94. La expresión entrecomillada (weak minds, en el original) está tomada de McLynn, 2008, p. 174. 


\section{IMÁGENES}

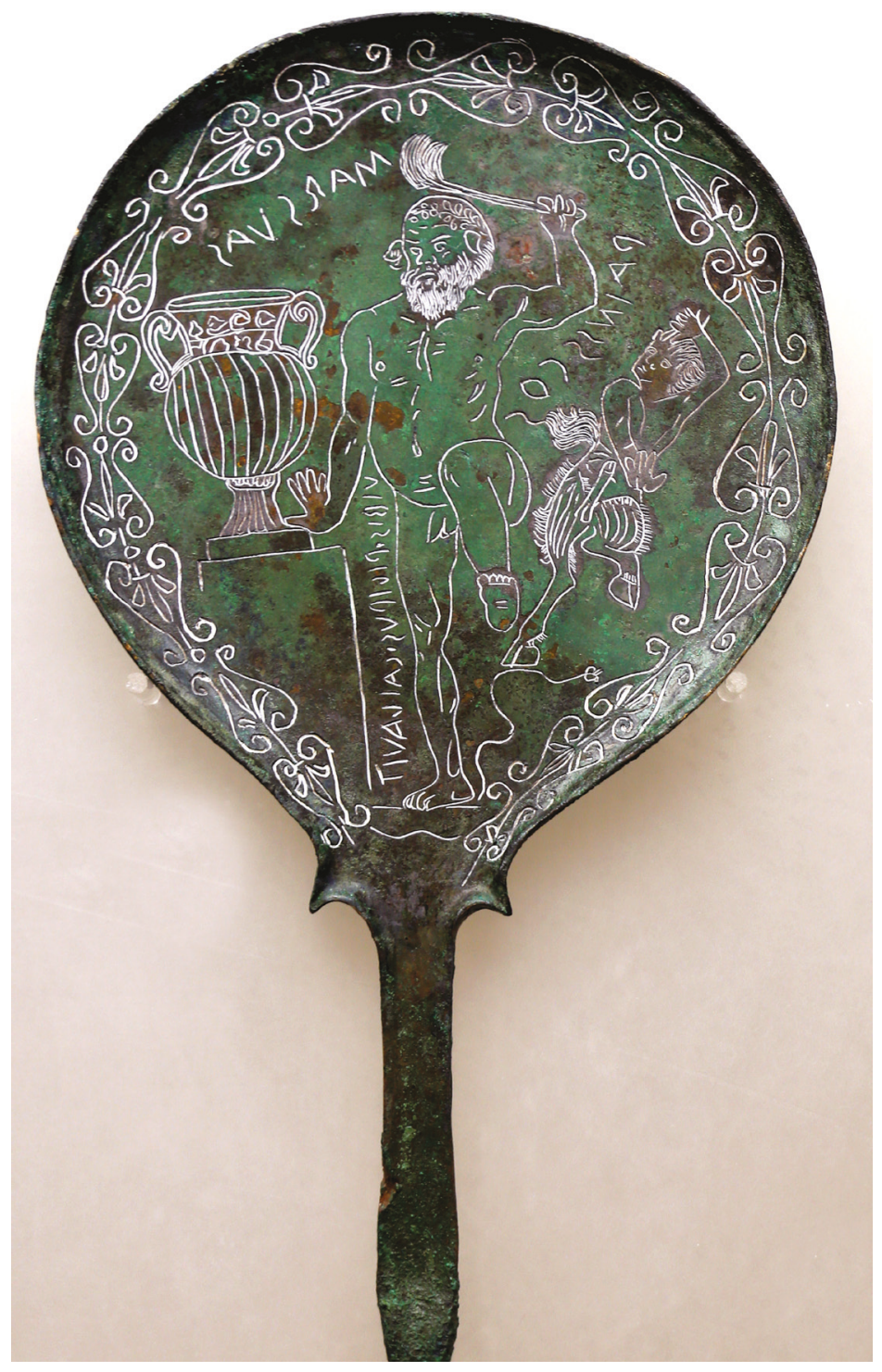

Fig. 1. Espejo etrusco que nos muestra al dios Pan junto a Marsias. Praeneste, ca. 325-300 a.C. Roma, Villa Giulia, Museo Nazionale Etrusco, inv. 2489.

Ministero per i beni e le attività culturali e per il turismo Museo Nazionale Etrusco di Villa Giulia 


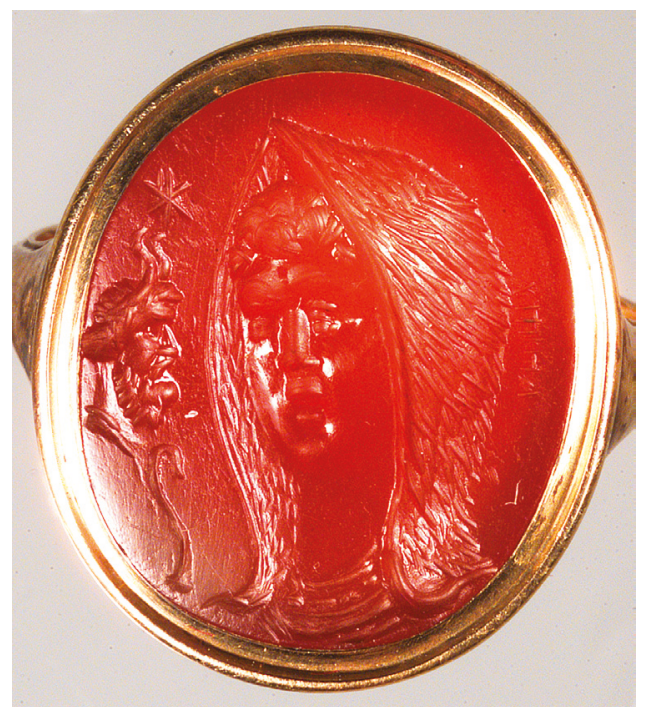

Fig. 2. Gema con cabeza de mujer y atributos alusivos al dios Fauno. Mediados del siglo I a.C. Viena, Kunsthistorisches Museum. H. 1,55 cm; B. $1,30 \mathrm{~cm}$; D. 0,37 cm. Antikensammlung, IXb 448. KHM-Museumsverband

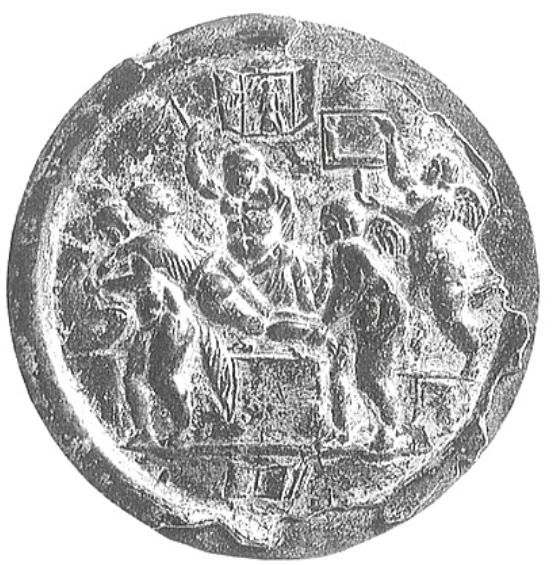

Fig. 3. Luperco (o Fauno) azotando a Venus. Siglos II-III d.C. Subastado en Nueva York, colección particular. 


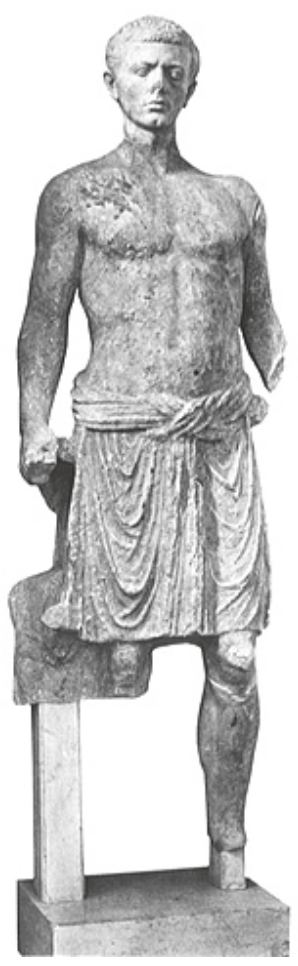

Fig. 4. Estatua de mármol blanco que representa a un luperco. Primer tercio del siglo I d.C. H. $177 \mathrm{~cm}$. Museo Civico di Fondi.

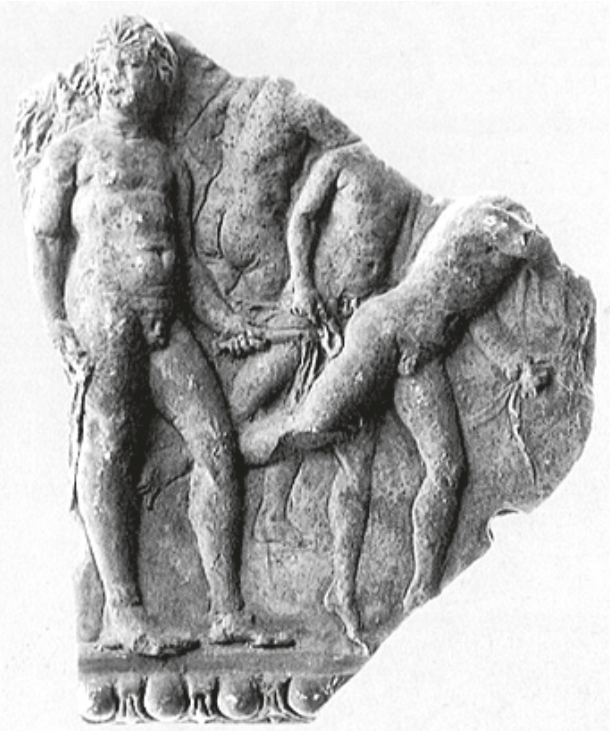

Fig. 5. Placa de arcilla que muestra a un luperco desnudo. Época Augústea (procedente de la Casa de Livia). H. $35 \mathrm{~cm}$;

L. $25 \mathrm{~cm}$. Museo Nazionale Romano, inv. 4359. Ministero per i beni e le attività culturali e per il turismo - Museo Nazionale Romano. 

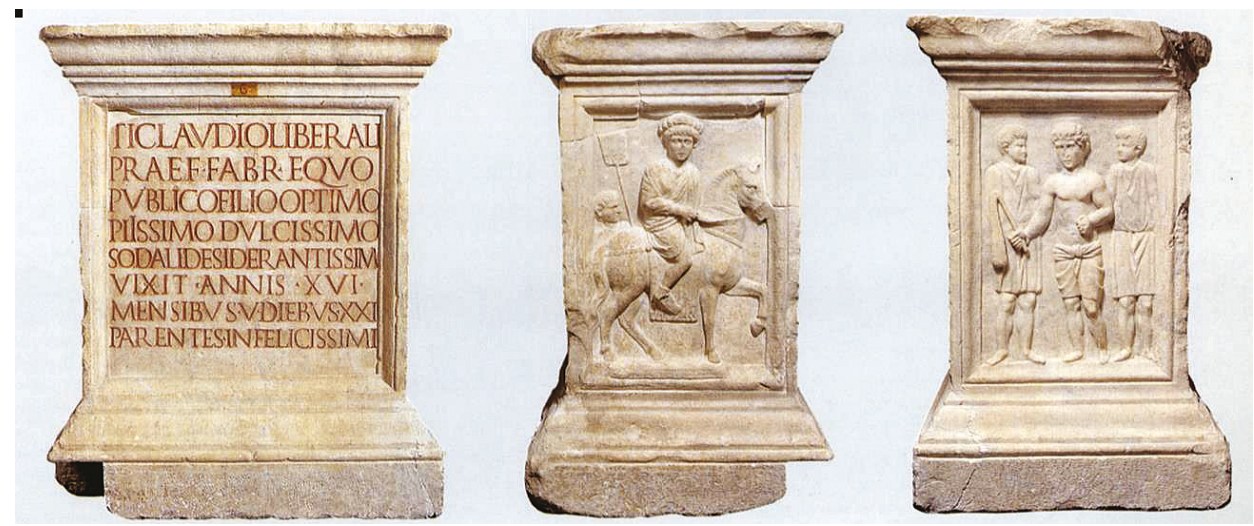

Fig. 6. Tres de las cuatro caras del altar de Ti[berius] Claudio Liberalis. CIL VI 3512 = XIV 3624. Inicios del siglo II d.C. H. 90 cm; L. 73 cm; P. 56 cm. Museos Vaticanos, Galería Lapidaria, inv. 9312.

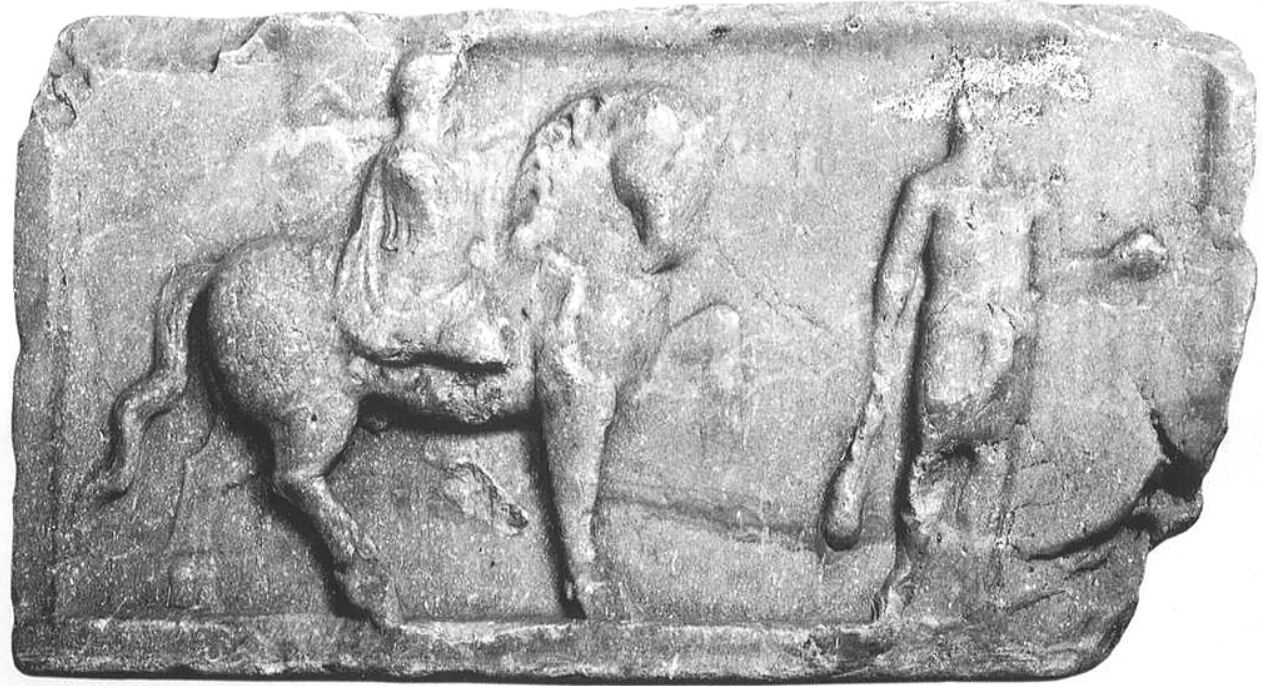

Fig. 7. Relieve de luperco (a la derecha). Siglo II d.C. H. 90 cm; L. $180 \mathrm{~cm}$. Museo del Sannio de Benevento, inv. 608. 


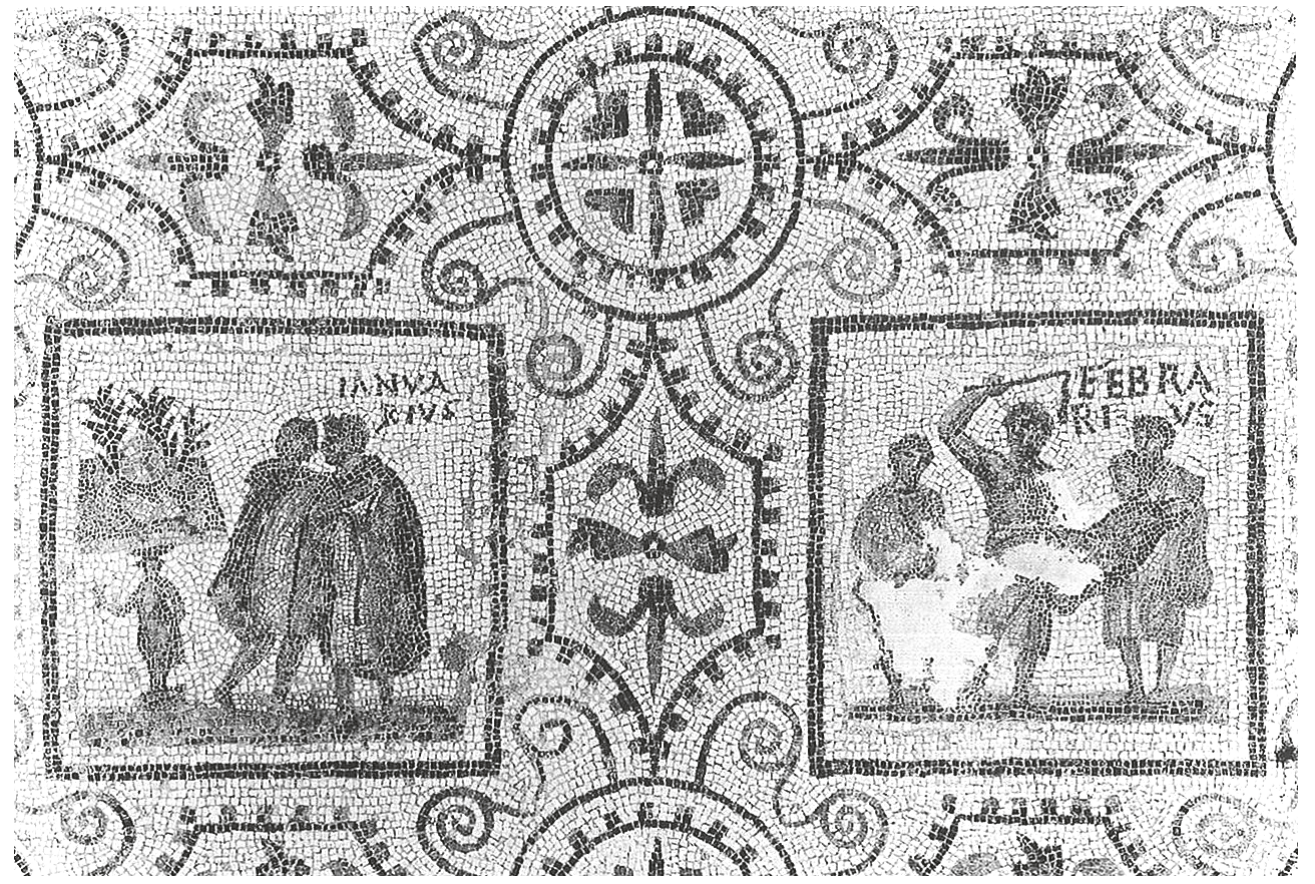

Fig. 8. Mosaico de Thysdrus (el-Djem, Túnez). Primera mitad del siglo III d.C. H. $400 \mathrm{~cm}$; L. $505 \mathrm{~cm}$. Museo de Sousse.

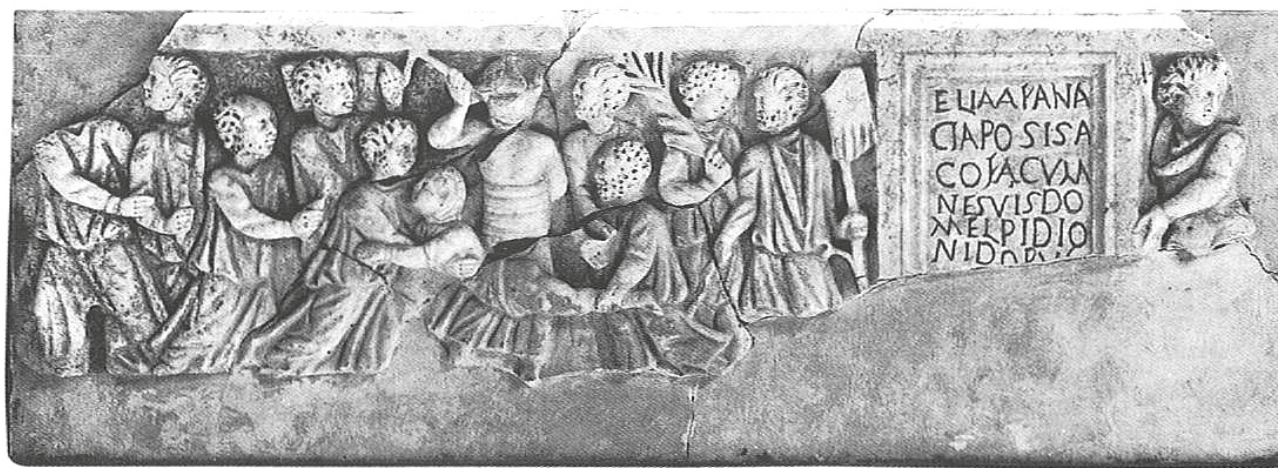

Fig. 9. Sarcófago de Elia Afanacia. Finales del siglo III d.C. (imagen); mediados del siglo IV (inscripción). H. 37 cm; L. $178 \mathrm{~cm}$; P. 5,5 cm. Museo classico delle Catacombe di Pretestato (Roma), inv. PCAS Pre 273. @ ) foto Pontificia Commissione di Archeologia Sacra. 


\section{Bibliografía 95}

Alföldy, A. (1974). Die Struktur des voretruskischen Römerstaates. Heidelberg: C. Winter. Alonso, Z. (2017). Re-Thinking Lupercalia. From Corporeality to Corporation. Greek and Roman Musical Studies, 5, pp. 43-62.

Bajtin, M. (1968 [1965]). Rabelais and His World. Cambridge: MIT Press.

Binder, G. (1964). Die Aussetzung des Königskindes. Meisenheim: Hain.

Bonfante, L. (1989). Nudity as a Costume in Classical Art. AJA, 93, 4, pp. 543-570.

Brelich, A. (1976). Tre variazioni romane sul tema delle origini. Roma: Edizioni dell'Ateneo.

Cameron, A. (2011). The Last Pagans of Rome. Oxford: Oxford University Press.

Carandini, A. y Bruno, D. (2008). La casa di Augusto: dai 'Lupercalia' al natale. Bari: Laterza.

Carandini, A. y Capella, R. (eds.) (2000). Roma: Romolo, Remo e la Fondazione della Città. Milano: Electa.

Coarelli, F. (2005). I percorsi cerimoniali a Roma in età regia. En Greco, 2005, pp. 29-42.

Coarelli, F. (2012). Palatium. Il Palatino dalle origini all' Imperio. Roma: Quasar.

Connolly, J. (2007). Virile Tongues: Rhetoric and Masculinity. En Dominik y Hall, 2007, pp. 83-97.

Cordier, P. (2005). Nudités romaines. Un problème d' histoire et d'anthropologie. Paris: Les Belles Lettres.

Corsano, M. (1977). 'Sodalitas' et gentilité dans l'ensemble lupercal. RHR, 191.2, pp. 137-158.

Dominik, W. y Hall, J. (eds.) (2007). A Companion to Roman Rhetoric. Malden-Oxford: Wiley-Blackwell.

Dumézil, G. (1940). Mithra et Varuna. Essai sur deux representations indo-européennes de la souveraineté, Paris: Gallimard.

Faccenna, D. (1954). Statua di vittimario scoperta a Fondi. Arch.Cl., 6, pp. 23-42.

Ferri, G. (2010). Tutela urbis. Il significato e la concezione della divinità tutelare cittadina nella religione romana. Stuttgart: Franz Steiner Verlag.

Ferriès, M.-C. (2009). Luperci et Lupercalia de César à Auguste. Latomus, 68.2, pp. 373-392.

Finney P.C. (ed.) (2017). The Eerdmans Encyclopedia of Early Christian Art and Archaeology. Vol. 1 (A-J). Michigan: William B. Eerdmans Publishing Company.

Foucher, L. (1963). Flagellation et rites de fécondité aux Lupercales. ABPO, 83, pp. 273-280.

Franklin, A.M. (1921). The Lupercalia. New York: Columbia University.

Graf, F. (2015). Roman Festivals in the Greek East. Cambridge: Cambridge University Press.

Granger, F. (1895). Worship of the Romans Viewed in Relation to the Roman Temperament. London: Methuen.

95. Las abreviaturas de las publicaciones periódicas siguen las convenciones de L'Année Philologique. Vid https://aboutbrepolis.files.wordpress.com/2018/09/aph_abbrc3a9viations.pdf [Consultada el 22-72019]. 
Greco, E. (ed.) (2005). Teseo e Romolo. Le origini di Atene e Roma a confronto. Atti del Convegno Internazionale di Studi. Scuola Archeologica Italiana di Atene. Atene, 30 giugno - 1 iuglio 2003. Atene: Scuola Archeologica Italiana di Atene.

Green, W.M. (1931). The Lupercalia in the Fifth Century. CPh, 26.1, pp. 60-69.

Gros, P. y Gras, M. (eds.) (1976). L’Italie préromaine et la Rome républicaine. Mélanges offerts à Jacques Heurgon, II, Roma: École française de Rome.

Guarisco, D. (2015). Augustus, the Lupercalia and the Roman Identity. Acta Ant. Hung, 55, pp. 223-228.

Hallett, C.H. (2005). The Roman Nude. Heroic Portrait Statuary 200 BC-AD 300. Oxford: Oxford University Press.

Harper, K. (2013). From Shame to Sin. The Christian Transformation of Sexual Morality in Late Antiquity. Cambridge (Mass.): Harvard University Press.

Holleman, A.W.J. (1974). Pope Gelasius I and the Lupercalia. Amsterdam: Adolf M. Hakkert.

Holleman, A.W.J. (1985). Lupus, Lupercalia, Lupa. Latomus, 44, pp. 609-614.

Joseph, N. (1986). Uniforms and Non-uniforms: Communitation through Clothing. New York: Greenwood Press.

Koch, G. (2017). S.v. 'Flagellation'. En Finney, 2017, p. 537.

Köves-Zolauf, T. (1990). Romische Geburtsriten. Zetemata, 87, pp. 221-289.

Krešimir, V. (2016). Roman Myth and Ritual: Groups of Luperci and Epigraphic Evidence. Epigraphica, 78, pp. 43-52.

Krešimir, V. (2017). The Topography of the Lupercalia. PBSR, 86.4, pp. 1-24.

Marco Simón, F. (1996). Flamen Dialis. El sacerdote de Júpiter en la religión romana. Madrid: Ediciones Clásicas.

Mayorgas Rodríguez, A. (2010). Romulus, Aeneas and the Cultural Memory of the Roman Republic. Athenaeum, 98, pp. 89-109.

McLynn, N. (2008). Crying Wolf: The Pope and the Lupercalia. JRS, 98, pp. 161-175.

Michels, A.K. (1953). The Topography and Interpretation of the Lupercalia. TAPhA, 84, pp. 35-59.

Muccigrosso, J. (2006). Religion and Politics: Did the Romans Scruple about the Placement of their Temples? En Schultz y Harvey, 2006, pp. 181-206.

Munzi, M. (1994). Sulla Topografia dei Lupercalia: il contributo di Constantinopoli. SCO, 44, pp. 347-364.

Negri, M. (1982). Lupi Sabinorum linguae vocantur hirpi. Acme, 35, pp. 199-203.

Néraudau, J.-P. (1979). La Jeunesse dans la Littérature et les institutions de la Rome républicaine. Paris: Les Belles Lettres.

North, J.A. (2008). Caesar at the Lupercalia. JRS, 98, pp. 144-160.

North, J.A. y McLynn, N. (2008). Postscript to the Lupercalia: From Caesar to Andromachus. JRS, 98, pp. 176-181.

Pérez Jiménez, A. y Del Cerro Calderón, G. (eds.) (1999). Estudios sobre Plutarco: obra y tradición. Actas del I Symposion español sobre Plutarco (Fuengirola, 1988). Málaga: Universidad de Málaga. 
Pomarès, G. (1959). Gelase I. Lettre contre les lupercales, Paris: Éditions du Cerf.

Porte, D. (1976). Note sur les luperci nudi. En Gros y Gras, 1976, pp. 817-824.

Potscher, W. (1984). Die Lupercalia. Eine Strukturanalyse. GB, 11, pp. 221-249.

Preller, L. (1858). Römische Mythologie. Berlin: Weidmann.

Rissanen, M. (2012). The Hirpi Sorani and the Wolf Cults of Central Italy. Arctos, 46, pp. 115135.

Robinson, M. (2011). A Commentary on Ovid's Fasti, Book 2. New York: Oxford University Press.

Rose, H.J. (1948). Ancient Roman Religion. London: Hutchinson's University Library.

Rüpke, J. (ed.) (2011). The Roman Calendar from Numa to Constantine: Time, History, and the Fasti. Malden y Oxford: John Wiley \& Sons.

Schultz, C.E. y Harvey, P.B. (eds.) (2006). Religion in Republican Italy. Cambridge: Cambridge University Press,

Schumacher, W.N. (1968-1969). Antikes und Christliches zur Auspeitschung der Elia Afanacia. JbAC, 11-12, pp. 65-75.

Solin, H. y Brandenburg, H. (1980). Paganer Fruchtbarkeitsritus oder Martyriumsdarstellung? Zum Grabrelief der Elia Afanacia im Museum der Prätextat-Katakombe zu Rom. $A A$, s.n., pp. 271-284.

Squire, M. (2011). The Art of the Body. Antiquity and Its Legacy. London y New York, I.B. Tauris.

Stern, H. (1968). Un calendrier romain illustré de Thysdrus (Tunisie). En Atti del Convegno Internazionale sul tema: Tardo antico e alto medioevo. La forma artistica nel passaggio dall'antichità al medioevo (pp. 177-200). Roma: Accademia Nazionale dei Lincei.

Tomey, M.A. (1999). Scavi francesi sul Palatino. Le indagini di Pietro Rosa per Napoleone III (1861-1870). Roma: École Française de Rome.

Toner, J. (1995). Leisure and Ancient Rome. Oxford y Cambridge: Polity Press.

Tortorella, S. (2000). Luperci e Lupercalia. La documentazione iconográfica. En Carandini y Capella, 2000, pp. 244-255.

Ulf, C. (1982). Das römische Lupercalienfest: ein Modellfall für Methodenprobleme in der Altertumswissenschaft. Darmstadt: Wiss. Buchges.

Ustinova, Y. (2009). Caves and the Ancient Greek Mind. Oxford: Oxford University Press.

Vé, K.K. (2018). La cité et la sauvagerie: les rites des Lupercales. DHA, 42.2, pp. 139-190.

Vera Muñoz, A. (1990). El método de Plutarco en el estudio de la fiesta lupercalia: Aet. Rom. 68, Rom. 21.3, Caes. 61 y Ant. 12. En Pérez Jiménez y Del Cerro Calderón, 1990, pp. $179-186$.

Veyne, P. (1960). Iconographie de la “transvecio equitum" et des Lupercales. REA, 62, pp. 100110.

Vogt, A. (ed.) (1935-1940). Constantin VII Porphyrogénète: Le livre des cérémonies (2 vols). Paris: Les Belles-Lettres.

Von Rohden, H. y Winnefeld, H. (1911). Architektonische römische Tonreliefs der Kaiserzeit. Berlin-Stuttgart: Verlarg Von W. Spemann. 
Wiseman, T.P. (1995a). The God of the Lupercal. JRS, 85, pp. 1-22.

Wiseman, T.P. (1995b). Remus: A Roman Myth. Cambridge y New York: Cambridge University Press.

Wiseman, T.P. (2004). The Myths of Rome. Exeter: University of Exeter Press.

Wrede, H. (1983). Statuae Lupercorum habitu. MDAI, 90, pp. 185-200.

Wrede, H. (1995). Der Venus Felix peinvolles Schicksal im Lupercal. MDAI(R), 102, pp. 345347.

Ziolkowski, A. (1998-1999). Ritual Cleaning up of the City: from the Lupercalia to the Argei. AncSoc, 29, pp. 191-218. 